\title{
Ecosystem Biomimetics for resource use optimization in
}

\section{buildings}

Keywords: Biomimetics, Biomimicry, Ecological engineering, Ecomimetics, Ecological design, Systems thinking, Sustainable design.

\section{Introduction}

The term biomimetics has been defined as the emulation of nature (Benyus, 1997), and also as the transfer of knowledge from nature to the engineering fields (Gruber, 2011b). Finding inspiration in nature is not a new concept, for instance Leonardo DaVinci's drawings of flying machines are often cited as examples of biomimetic exercises (Gebeshuber, Gruber, \& Drack, 2009). However, only during the last decades has the biomimetic approach started to become more formalized in architecture and design (Lepora, Verschure, \& Prescott, 2013). The assumption underlying biomimetic design is that nature has reached a high level of specialization because it has evolved for billions of years, and therefore there is great potential for improvement in human technology by mimicking biological systems (Benyus, 1997). Recently the biomimetic approach has been presented as an innovative method for sustainable design in architecture. This assumption originates from the idea that biological systems deal efficiently and effectively with natural resources (John, Clements- Croome, \& Jeronimidis, 2005). However, biomimetic designs can have 
adverse environmental effects if designers do not place a conscious emphasis on sustainability during their development (Gebeshuber et al., 2009). For example, the fabrication of Velcro (product inspired by burrs) is an energy-intensive process that uses synthetic polymers like nylon fibers.

With regard to environmental issues, buildings and the building industry are accountable for a large proportion of global resource use (30\% of raw material and $40 \%$ of energy use) and pollution (one third of greenhouse gas emissions) (UNEP, 2009, 2010). The field of 'sustainable architecture', with its multiple approaches and nuances, aims to address these issues. The research presented here aligns with Guy and Farmer's (2001) interpretation, who consider 'sustainable design' as a broad heterogeneous field with room for integrating different practices. According to that work, the ecotechnic approach is one of the logics of sustainability. It relies on technological development to produce sustainable buildings that reduce the use of raw materials and energy, as well as reduce undesirable emissions such as greenhouse gases (GHG). This ecomimetic research aligns with these goals, but also acknowledges the multiple facets of sustainable architecture and the benefits of integrating other logics of sustainability. In this regard, this work also aligns with ecocentric logic as defined by Guy and Farmer, which puts value on ecological systems and measures the success of sustainable design according to the health of our ecosystems. Along this line of thought, other authors, such as Mang and Reed (2014), characterized the biocentric approach as that which first identifies a place's ecology and which involves a deep understanding of the multiple interactions in the 
ecosystem and the patterns that emerge from them. Net positive design, regenerative design, and some integrative design processes fall into this category as well (Cole, 2012; Mang \& Reed, 2014). Beyond the ecotechnic and ecocentric approaches, Guy and Farmer (2001) identify other logics of sustainability that focus on the ideas of complexity and non-linear dynamics, or that give high priority to a healthy environment. The integration of different perspectives helps to enrich the field of sustainable architecture, especially given that there is not an absolute definition but rather many approaches to sustainability (Guy \& Farmer, 2001). According to this understanding of sustainable design, biomimetic design might follow the eco-technic logic in the development of products, processes, and materials, but it may also have a strong component of eco-centric sustainability as well as the other aspects mentioned above.

This work aims to develop a general design method based on ecosystem biomimetics. The purpose of this method is to learn from exemplary ecosystems and transfer relevant processes and functions to optimize resource use in buildings. In the context of this research the term 'resource' refers to different forms of energy, materials, and information that are regulated by both ecological and building systems. There are multiple definitions of 'ecosystem'. The Convention of Biological Diversity defines an ecosystem as:

A dynamic complex of plant, animal and microorganism communities, and their nonliving environment interacting as a functional unit (United Nations, 1992). 
This definition is used by the United Nations Environment Program (UNEP), the Intergovernmental Panel on Climate Change (IPCC), and also in the reports of the Millennium Ecosystem Assessment. The definition given by Odum (1994) also fits very nicely in the context of this work:

An organized system of land, water, mineral cycles, living organisms, and their programmatic behavioral control mechanisms

At the core of many definitions of ecosystem is the idea of a "hierarchy of levels of integration" (Pomeroy \& Alberts, 1988). This idea refers to the fact that ecosystems are nested, complex systems that manifest across temporal and spatial scales. Ecology has been defined as a holistic science (Odum, 1977), but it also is reductionist in that one sometimes needs to look at the details in order to understand the functioning of an ecological process (Pomeroy \& Alberts, 1988)

The work presented here aims to help implement ecosystem biomimetic design in architectural practice. There is a considerable amount of work developed in this area by Pedersen Zari (2012). Her work identifies strategies and techniques for mimicking functions and processes of ecosystems and their implementation in the built environment. In this context, 'functions' are what ecosystems can do (e.g. pollination) and 'processes' are the strategies that enable the functions (e.g. self-organization). Pedersen Zari describes extensively what aspects of ecosystems can be transferred to the built environment, whereas the research presented here offers an explanation of how this might be 
done. This work is intended to provide designers with concrete tools for ecosystem biomimetic design. This is a multilevel and hierarchical approach to the study of ecosystems, because there is a constant zooming in and out from specific functions (e.g. pollination) to the multiple processes which combine to give rise to the overall behavior of the ecosystem.

This work expands on Pedersen Zari's work in that the principles that she identified for mimicking ecosystems can be integrated into the design method proposed here.

This document starts with a brief classification of biomimetic research, and a description of methods and tools currently being used. The ecomimetic method is then described with an explanation of the theoretical basis of each stage of the method and a case study to illustrate its application. The document closes with a discussion of the opportunities and challenges of the ecomimetic approach and the future development of the method.

\section{Classifications in biomimetic research}

Classifications of biomimetics have focused frequently on the outcomes obtained from biomimetic research. Petra Gruber (2011b) uses the classification made by Nachtigall (1997) which consists of three main fields: structural biomimetics (i.e. constructions and materials in nature), procedural biomimetics (i.e. processes in nature) and informational biomimetics (i.e. principles of evolution and information transfer in nature) (Gebeshuber et al., 2009). Ayre's (2004) work for the European 
Space Agency points out the difficulties in classifying biomimetics and the inevitability of some overlap between categories, which might be understood as a reflection of the complexity of biological systems. The categories defined in his report are: structures and materials; mechanisms and power; behavior and control; sensors and communication; and generational biomimetics (i.e. the biological processes that occur at the species and generational level rather than at the individual or group level). Finally, Pedersen Zari (2007) has classified biomimetic research in architecture according to two different outcomes. The first categorization shares the approach of Ayre's and Nachtigall's classifications, and it is based on the expression of the naturally inspired feature in one of five different architectural domains: form, material, construction, process and function. Biomimetic forms reproduce the appearance of a natural system, whereas the biomimetic materials imitate the matter from which a natural system is made. Biomimetic construction addresses how a natural system is built, biomimetic processes mimic how the system works, and biomimetic functions reproduce what the natural system can do. The second categorization by Pedersen Zari is centered on the organizational level of the elements of nature that are mimicked: organism, behavior and ecosystem. The first level, organism, encompasses architectural projects inspired by a single organism (e.g. a termite). The second level refers to buildings that mimic how an organism behaves (e.g. termites' activities). The third level, ecosystem, includes buildings that mimic the biotic and abiotic components of an ecosystem and the system-level interactions between its components (e.g. termite ecosystem). Pedersen Zari's work 
Author accepted version. Final publication as:

Garcia-Holguera, M., Clark, G., Sprecher, A., Gaskin, S.J. (2015) Ecosystem biomimetics for resource use optimization in buildings, Building Research and Information, 44(3):263-278.

doi:10.1080/09613218.2015.1052315

focuses on the third level and further develops a hierarchical network of interconnected processes that explain the complexity in nature (Pedersen Zari, 2012, 2014). The practice of ecosystem biomimetics is also known as ecomimetics. This document concentrates on ecomimetic research and its purpose is to present a method for mimicking ecosystems. Although biomimetic design and research in architecture increase exponentially during the last decade (Lepora et al., 2013), the field still lacks design methods that tackle biomimetic design from the ecosystem's perspective.

Therefore existing methods and tools in the biomimetic field have been used to define the ecomimetic method presented here.

\section{Biomimetic methods and tools}

Most of the work being developed by architects and researchers can be divided into three general categories:

- Development of the discipline through academic programs, courses, and experimental design case studies (Gruber, 2011b; Helms, Vattam, \& Goel, 2009; Lenau, 2009)

- Development of methods and design tools to support scientific and systematic research (Biomimicry 3.8 Institute, 2008; Cheong \& Shu, 2012; Pedersen Zari, 2011, 2012, 2014; Vincent, 2003; Vincent \& Mann, 2002)

- Real case studies developed by architectural firms (Turner \& Soar, 2008). In some cases architectural firms have built research groups, independently or in collaboration with institutions, to develop new approaches to sustainable design (Lazarus \& Crawford, 2011) 
Among these three lines of enquiry the most relevant for this research is the development of methods and design tools. Several of these design methods have served as inspiration for the ecomimetic method presented here, and others have been integrated into the method itself. A brief description of these approaches to biomimetic design is presented below.

- Bottom-up and Top-down approaches. Regardless of differences between various methods and tools, most researchers and experts agree that biomimetic design can be engaged from a bottom-up or top-down approach (Ayre, 2004; DTI, 2007; Gamage \& Hyde, 2012; Gruber, 2011a, 2011b; Helms et al., 2009; Jan \& Thomas, 2012; Pedersen Zari, 2007; Speck \& Speck, 2008). The bottom-up approach is also known as biomimetics by induction or as a solutionbased approach. The design process starts with the identification by biologists or ecologists of a biological system with interesting properties. Then, together with the design team, they adapt the biological properties into a human technology. The top-down approach, also known as biomimetics by analogy or a problembased approach, starts with a design problem detected by the design team. Solutions are sought in biology or ecology, and then implemented in products or processes.

- $\quad$ BioTRIZ is a tool for finding biological solutions to human problems (Vincent, Bogatyreva, Bogatyrev, Bowyer, \& Pahl, 2006). It is based on TRIZ, which is a tool for problem-solving that uses 40 design principles as a database of inventive solutions (Vincent \& Mann, 2002). Design problems are defined in 
pairs of contradictions that can be linked to one or more design principles.

Initially TRIZ did not include biological principles and BioTRIZ adds them to the database to foster the biomimetic field. The suggested sequence of steps for biomimetic design using BioTRIZ are: problem description; biological analogy finding or biological conflict matrix use; biological principles listed; new technology developed from the biological principles (Vincent et al., 2006). However, buildings are complex systems and the tool might not be able to take into consideration the multiple interactions among building components, and therefore it might not be appropriate for architectural biomimetic design (Gruber, 2011b)

- $\quad$ BioMAPS is a database developed at the University of Toronto (Shu, 2010) by the Biomimetics for Innovation and Design Laboratory (BIDLab). This database is to be used at the beginning of the biomimetic design process, and it helps to connect engineering terms with biological ones. The reference sources for BioMAPS are limited to the book "Life, the Science of Biology" by Purves (Purves, 2001) and Wikipedia. However, as of September 2014 the database is not active in the BIDLab website.

- $\quad$ Biomimicry 3.8 is a consulting company and institute leader in implementing professional and educational programs to promote biomimetic design. It has developed several methods and tools, some of them in partnership with the architectural firm HOK (Lazarus \& Crawford, 2011). The first one, the Ecological Performance Standards reflect the specific characteristics of the site 
where the biomimetic project is to be implemented and provide performance metrics of the site (Peters, 2011). The second one, the Fully Integrated Thinking (FIT) design methodology, aims to manage projects from a whole system perspective that covers environmental, social and economic aspects represented in 15 categories. Another approach being used at Biomimicry 3.8 are the biomimicry design spirals (Gamage \& Hyde, 2012; Hastrich, 2006), which are iterative design processes with a top-down or bottom-up orientation. The top-down approach also called "challenge-to-biology" consists of seven steps: identify; define; biologize; discover; abstract; emulate and evaluate. The bottom-up approach or "biology-todesign" comprises five steps: discover; abstract; brainstorm; emulate and evaluate (Peters, 2011). Additionally, Biomimicry 3.8 has developed an open source database called AskNature that classifies biological systems by functions and provides relevant information about each of the biological strategies (Biomimicry 3.8 Institute, 2008). Each strategy presented in AskNature comes with the following information: photo of the biological system being mimicked, biomimicry taxonomy, summary of the strategy, description of the biological system, list of products and application ideas, links to researchers and institutions working on the topic, and a list of publications on the topic. To the authors' knowledge this is currently the most exhaustive database for biomimetic research and design. However, one challenge when using databases for biomimetic research is to establish analogies between concepts and knowledge from biology to other design disciplines. Another challenge is to overcome problems related to 
misuse of keywords and the "management of the quantity and the quality of the matches" (Freitas Salgueiredo, 2013). It is expected that the use of

thermodynamic language and the focus on ecosystems rather than organisms will help to address these challenges. Additionally, researchers have identified common errors when searching for ecological solutions, such as: design goals vaguely defined; solutions not based on functionality; missing underlying principles; complex systems oversimplified; fixation on a solution; or erroneous interpretation of analogies (Helms et al., 2009; Shu, Ueda, Chiu, \& Cheong, 2011).

- $\quad$ Ecosystem for biomimetic design: Pedersen Zari $(2012,2014)$ has built a conceptual framework for mimicking ecosystems processes and functions. In both approaches, the author proposes a list and relationship matrix to guide designers through the process. Biomimicry of ecosystem processes, as presented by Pedersen Zari, has a generalist vocation in that it does not propose specific techniques, but rather sets a number of goals that designers have to achieve. According to this, any "existing method or technology can be used to meet those goals" (Pedersen Zari, 2012 pg.218). The author also studies ecosystem services in the context of the biomimicry of ecosystem functions. It is suggested that mimicking ecosystem services might be more straightforward because these are easier to understand, measure and report in a design environment. This work is relevant in that it is based on a scientific understanding of ecosystems, and also in 
Author accepted version. Final publication as:

Garcia-Holguera, M., Clark, G., Sprecher, A., Gaskin, S.J. (2015) Ecosystem biomimetics for resource use optimization in buildings, Building Research and Information, 44(3):263-278.

doi:10.1080/09613218.2015.1052315

that it proposes design goals centered on ecological measures rather than human measures.

\section{The Ecomimetic Method}

The ecomimetic method presented here has been developed taking into consideration the above-mentioned methods and tools. Additional tools from ecological engineering and systems dynamics have also been included in the methodology. The top-down approach has been deemed as appropriate because the target audiences for this method are students, researchers and designers in the architectural and engineering fields. This means that the design process starts with a design problem, and then the design team looks for a solution in nature. The method is portrayed as a spiral because we acknowledge the importance of iteration in biomimetic design for incorporating feedback and guiding further development. Also, like most design methods, it has two crucial stages focused on the abstraction and transference of biological principles. There are four main differences between the proposed ecomimetic method and the other methods described previously. First of all, the proposed method can incorporate databases from other biomimetic approaches. Second, it can integrate tools from ecological engineering and systems thinking. Third, it uses thermodynamic language for the abstraction and transference of properties. Finally, the proposed method is specialized for use with ecological systems. A graphic representation of each of the stages of the ecomimetic method is presented in Fig. 1. 


\section{[Figure 1]}

The Eastgate Center building has been selected as a hypothetical case study to illustrate the application of the ecomimetic method. The Eastgate Center, designed by Mick Pearce in 1996 and located in Harare (Zimbabwe), is recognized as a built example of biomimetic architecture (Fayemi, Maranzana, Aoussat, \& Bersano, 2013; Pedersen Zari \& Storey, 2007; Turner \& Soar, 2008; Wasfi, 2014; Wilson, 2008). The building mimics several characteristics of a termite mound in order to optimize heating and cooling performance in the building. First, it has stacks that connect the open spaces in the building. Through these channels volumes of fresh air circulate thanks to a forced ventilation system that simulates the induced flow in open termite mounds. Second, it uses the thermo-siphon mechanism by circulating the hot air from occupants, machinery and the building itself toward the rooftop stacks. Finally, the building also uses its thermal capacity to refresh the building's temperature in the night. To facilitate the process, the forced ventilation system is used to extract the heat accumulated during the day by the building's thermal mass. Although the building does not work exactly as a termite mound in many ascpects, it includes several strategies inspired by termite mounds in a single building system (Turner \& Soar, 2008).

\section{Stage 1 - Architectural design goals}

In the first step of the ecomimetic process one or several design objectives are identified. The formulation of these design goals needs to:

- Be expressed in a thermodynamic language; 
- $\quad$ Address buildings' resource use issues and specific contextual environmental issues.

Buildings are thermodynamic systems that have to regulate inflows and outflows of resources (matter, energy, information), and ecologists and architects agree that both ecosystems and buildings are open thermodynamic systems (Allen, 2001; Fernandez-Galiano, 1991; Kibert, Sendzimir, \& Guy, 2000). Therefore, thermodynamics can be used to link biology and architecture. Researchers have pointed out that thermodynamic analysis of buildings has mostly used the first law, which focuses on quantities of energy flows; whereas the second law focuses on the quality of the energy flows (Kay 2001). It could be said that the first law of thermodynamics deals with efficiency and the second law deals with effectiveness. Interestingly, ecological systems might not be very efficient, but they are extremely effective in capturing useful energy (e.g. solar radiation). This suggests that, focusing on the second law of thermodynamics, which introduces concepts such as entropy and irreversibility, might be more appropriate when mimicking ecosystems. Buildings and ecosystems are dissipative structures, and need constant flows of high quality energy to conserve their structure and organization. High quality energy is can be used to perform work, and is signified by the term "exergy". The combination of creative processes (exergy inflows) and destructive processes (entropy outflows) produces the multiple steady states that occur in ecological and building systems. These systems capture exergy a during their maintenance and self-organization. By using inflows of exergy to create ordered structures, dissipative systems move away 
from thermodynamic equilibrium (Prigogine, 1968). Kay and his colleagues (Kay, 2001; Kay, Regier, Boyle, \& Francis, 1999) referred to dissipative structures in natural systems as Self-Organized Hierarchical Open Systems or SOHO systems conform to the laws of thermodynamics in that they still tend towards thermodynamic equilibrium, but that they use exergy inputs to counter this tendency. Exergy rather than energy has therefore been considered a more appropriate theme for the discussion of thermodynamics in ecological systems, in part because the concept of exergy helps to conceptualize the departure of a system from thermodynamic equilibrium (Dewulf et al., 2008; Jørgensen \& Svirezhev, 2004). Another relevant idea is that of embedded energy or "emergy", introduced by Howard Odum (Brown, 2004; Odum, 1994, 2001). Emergy refers to the amount of one type of energy that is necessary in a given system to produce one unit of another type of energy; for example, the amount of solar radiation implicated in the biogeochemical formation of one barrel of crude oil. Emergy has been used to analyze the energy hierarchy of ecological systems and it has been proposed as a means to assess the energy hierarchy of buildings (Odum, 1994). Emergy analysis has also been implemented to maximize renewable resource use in buildings (Srinivasan, Braham, Campbell, \& Curcija, 2012), to conduct Life Cycle Assessment (LCA) in buildings (Srinivasan, Ingwersen, Trucco, Ries, \& Campbell, 2014), or to evaluate eco-efficiency of building manufacturing (Li, Zhu, Hui, Leung, \& Li, 2011). The use of thermodynamic approaches in ecological systems and architectural systems is not new. In the past, architects have stated similar interpretations of the second law of thermodynamics in 
the context of resource use of buildings (Fernandez-Galiano, 1991; Mumford, 1934), and it appears that thermodynamics could be an appropriate means to convey relevant concepts from ecology to architecture.

In addition to using a thermodynamic language in the enunciation of the problem, the design goals have to address environmental concerns as well. The appropriateness of the ecomimetic method will be measured in terms of its capability to optimize resource use in buildings so as to mitigate global environmental problems such as GHG emissions, water accessibility, land sprawl, air quality, or resource depletion for example. The acknowledgement of environmental problems can be tackled from two perspectives: considering external conditions (e.g. local ecosystems.) and considering project specific conditions (e.g. building use, building surface, materials, building envelope, etc.). When addressing external conditions several lines of research might be relevant. Regenerative design gives a central role to the understanding of place, meaning that it is vital "for organizing how the project needs to work as a living system nested in its place" (Mang, Reed; 2012). Pedersen Zari's approach to ecosystem services for the design of regenerative built environments also proposes that local ecosystems be studied to identify design targets (Pedersen Zari, 2012). The HOK-Biomimicry Group team proposes the identification of the specific characteristics of a place, and the description of ecological performance standards for that place at the beginning of the design process (Lazarus 2011). The ecomimetic method presented here can benefit if designers integrate these approaches when identifying the design goals. By doing so the results of the ecomimetic design process 
will have a greater connection to the specific place where the project is built.

However, there might be situations in which knowledge can be gained from

ecological systems that are not local, but whose properties might be relevant to the project under development. The ecomimetic method can also embrace these 'nonplace centered' design approaches.

\section{Eastgate Center-Design goals}

The Eastgate Center is located in Zimbabwe, which has a subtropical highland climate with low average annual temperatures due to its altitude and cool winds. Minimum temperatures range between $7^{\circ} \mathrm{C}$ and $16^{\circ} \mathrm{C}$ and maximum temperatures range between $21^{\circ} \mathrm{C}$ to $28^{\circ} \mathrm{C}$. Daily temperature can vary up to $15^{\circ} \mathrm{C}$ in winter and $10^{\circ} \mathrm{C}$ in summer (BBC Weather, 2013). These climate conditions suggest that heat gains rather than heat losses in the building will have to be overcome. For the purposes of this case study it will be assumed that air conditioning systems will not be implemented in the building in order to minimize energy use and reduce GHG emissions. In consideration of all the above, the building system will have to be able to regulate temperatures in the building throughout the year and guarantee thermal comfort for its users in a range between $18^{\circ} \mathrm{C}$ and $23^{\circ} \mathrm{C}$.

\section{Stage 2 - Ecological solution searching}

The next step is to search for one or several ecological systems whose behaviors address the design goals. If the local ecosystem was identified as the most appropriate for the ecomimetic exercise, then the design team can go to Stage 3 of this method; otherwise, it is suggested that they use databases that are intended for biomimetic 
design, and that at the same time are able to accept and recognize a thermodynamic language. Two of these databases have been mentioned above (i.e. BioMAPS and AskNature). Other databases are mentioned in the paper by Fayemi et al. (2013); however, some of these databases have been discontinued such as the one from the European Space Agency (bionics2space), and some others are difficult to access (e.g. Data_Bionik or BioPS are in German and Data_Bionik has restricted access). In addition to using databases, other approaches for finding ecological solutions include asking biologists or ecologist directly, and using a natural-language search as suggested by Shu et al. (2011). For the purposes of this document, the AskNature database will be used to look for ecological systems, but the other approaches will be considered in future work.

\section{Eastgate Center-Ecological solution searching}

The keyword 'regulate temperature' was introduced in the AskNature database. The search provided more than 300 biological strategies (database access March 24, 2014). From these, a group of seven strategies working at the ecosystem level were selected; such as wood ants organizations, honeybees hives or termite mounds. In this case, the termite mound ecosystem, the ecological system that was used for the biomimetic design of the Eastgate Center, was selected. In other design processes the selection of the appropriate ecosystem might consider the specific location and climate conditions affecting the building and the ecosystem, the amount of available and understandable information about the ecological system, or the effectiveness of the ecosystem when addressing the design goals for example. 
Complementary information about the selected ecosystem has to be gathered to acquire a deep understanding of the functioning of a termite mound (Jacklyn, 1992; Kofoid, 1934; Schmidt, Jacklyn, \& Korb, 2014; Turner, 2001; Turner \& Soar, 2008; Worall, 2011). At this stage it is also recommended to invite ecologists and/or biologists, who might provide more insight about the system under study. Difficulties might arise if there is not enough information or the information available is not accessible to the design team. When this happens, other pre-selected ecosystems (e.g. wood ants instead of termite mounds) will be considered for study as part of an iterative design process.

\section{Stage 3 - Abstraction and representation of ecological systems}

The abstraction phase is crucial for the success of the design process. Components and parameters intervening in the ecosystem's behavior have to be identified, as well as relevant information and complex interactions (Gruber, 2011a, 2011b; Helms et al., 2009). This research focuses on resource use; therefore, representation of flows of energy, materials and information are at the core of the abstraction exercise. Most biomimetic methods use language approaches to abstract functions observed in biological systems (Freitas Salgueiredo, 2013; Helms et al., 2009); however, the ecomimetic method uses a graphic tool from ecological engineering and an environmental modeling tool based on systems thinking theories. These tools have shown potential for transdisciplinary representation of ecosystems and building systems (Authors, 2012) and are able to convey meaningful information from one discipline to the other. 
The first tool, the Energy Systems Diagram (ESD) was developed by Howard Odum (Odum, 1994) to graphically represent the flows of energy and structural organization of environmental systems. The ESD simultaneously shows multiple energetic interactions that would otherwise be described with verbal models (Odum $\&$ Peterson, 1996). Their usefulness has been appreciated in fields such as open systems thermodynamics, general systems theory, and simulation (Brown, 2004). Odum used ESDs to characterize a city and also to represent a family house system (Odum, 1994; Odum, 2007), while other researchers have used the ESD for emergy analysis in buildings (Srinivasan et al., 2012). Consequently, proposing that the ESD be used for the representation of building systems is not new, but the application of the ESD within the framework of biomimetic research is. Each ESD has a boundary that separates the external sources of energy from the components of the system. The components can be state variables and energy flows. State variables are each represented with specific symbols according to the function they perform in the system, and similarly the flows of energy have diverse graphical representations. The diagrams show the interactions among components and the feedback loops that reinforce the behavior of the system. For a more detailed description of the ESD and its application for building representation refer to (Authors, 2012).

The second tool is STELLA, a software tool mostly used in the field of environmental modeling. Its origins are in Forrester's systems dynamics theories (Forrester, 1995). Further development of his work has focused on computer simulation modeling strategies. STELLA can facilitate understanding of the dynamic 
behavior of complex systems (Ford, 2010). Buildings and ecosystems behave as complex systems in that their outputs do not stem from linear interactions but rather are the result of multiple and complex feedback loops. Systems with different components and interactions might share general functional principles and, despite differences in their external appearance, systems with similar feedback loops might show similar dynamic behaviors (Meadows \& Wright, 2008; von Bertalanffy, 2008). This supports the idea that despite the differences between ecosystems and buildings, it is possible to mimic ecosystems' dynamic behaviors in buildings if they are designed with similar feedback structures to those observed in ecological systems. Examples and guidance for developing dynamic models with STELLA are provided by Ford (2010), and published work is found in the journal Ecological Modeling.

\section{Eastgate Center - Abstraction and representation.}

At this stage, the selected ecosystem, the termite ecosystem, is represented using the ESD and the STELLA software. The ESD is used for the visualization of the structure and organization of the termite mound, as well as for the representation of the feedback loops that participate in the thermal regulation of the ecosystem. Fig. 2 illustrates one of the possible ESDs that might arise at this phase. Other ESDs might be developed as part of the iterative process and it is expected that different design teams might produce different ESDs for the same ecosystem.

\section{[Figure 2]}

The environmental modeling tool, STELLA, is used to build a model to simulate the behavior of a termite mound ecosystem through time, and shows how the 
ecosystem reaches thermal stability. Before running the simulation, a conceptual model is built very similar to the ESD (Fig.3). An important difference with the ESD is that each parameter of the conceptual model is assigned a value that defines the starting conditions of the model. During this process of calibration some values may be easily accessible (e.g. average temperatures), whereas others might require preliminary estimations and adjustments through sensitivity analysis (Blanco, 2010).

\section{[Figure 3]}

The model is tested to ensure that the simulation exhibits the performance observed in the termite mound. Fig. 4 shows that the termite mound maintains a quite stable temperature despite the external variations.

\section{[Figure 4]}

At the end of this stage the design team has a deep understanding of the ecological system under study. The design team can recognize the components intervening in the system, the relationships among these components and the feedback loops that support the dynamic behavior of the system.

\section{Stage 4 - Correlation between ecological systems and architectural systems}

The components from both the ecological systems and the architectural systems are classified according to their functions. The goal at this stage is to find one or several correlations between the function performed by a component in the ecological system and the function performed by another component in the architectural system. For example soil performs a key role in filtering rainwater. It both purifies water and 
helps in runoff water regulation. In a similar way, when a green roof is implemented in a building system it is able to perform, among other things, these same purifying and regulating functions. The establishment of these equivalencies is important because, as stated above, systems with similar feedback structures might show similar behaviors. Therefore, identifying the appropriate architectural components that can be integrated in a building system to mimic the feedback structures observed in the ecosystem is critical to the success of the design process. The identification of architectural components and the search for a correlation of functions is an iterative exercise. On some occasions, more than one architectural component will be able to perform the expected function, and the design team will have to select among the available components by prioritizing sustainable criteria. On other occasions no architectural component will be known to perform the desired function, and this will open opportunities for innovation through the development of such a component.

This phase is closely related to the ESD. In the ESD, components are initially classified according to their functions as source, storage, producer, or consumer units, for example. This simplification of functions is very useful in the representation of energy flows and when trying to find correlations among ecological and architectural components (Authors, 2012).

\section{$\underline{\text { Eastgate Center-Correlation }}$}

For the Eastgate Center case study, Table 1 represents the correlation between some ecosystem and building components. There is more than one correct set of 
functional equivalencies, and different approaches to the same problem might convey different and valuable solutions.

\section{[Table 1]}

\section{Stage 5 - Transference of ecosystem's principles to an architectural system}

At this stage the aim is to define an architectural system whose dynamic behavior mimics the performance of the selected ecosystem. At the end of this phase, the design team will obtain a set of guidelines about how to create an ecomimetic building. These guidelines will provide advice about what components are needed in the architectural system, the relationships among these components, and the feedback structures that enable the desired dynamic behavior. The first step is to use the ESD to represent the hypothetical structure and organization of an architectural system. The ESD is built based on the correlation between the components, as described in the previous phase. The second step is to build a dynamic model (i.e. the STELLA model) based on the ESD, and to evaluate the model for its ability to reproduce the dynamic behavior of the termite mound. The model is expected to go through multiple iterations before a coherent architectural system shows the desired performance. Systems dynamics theories and modeling has been successfully used before in building and construction projects, such as optimization of construction management, design-build processes, or assessment of sustainable performance of buildings (Thompson \& Bank, 2010). It is expected that a systems dynamics approach will be also useful for biomimetic design processes. 
Author accepted version. Final publication as:

Garcia-Holguera, M., Clark, G., Sprecher, A., Gaskin, S.J. (2015) Ecosystem biomimetics for resource use optimization in buildings, Building Research and Information, 44(3):263-278.

doi:10.1080/09613218.2015.1052315

\section{$\underline{\text { Eastgate Center - Transference of ecosystem's principles }}$}

Fig. 5 presents a simplified ESD of a potential architectural system that incorporates the strategies for thermal regulation observed in the termite mound ecosystem.

\section{[Figure 5]}

Fig. 6 presents a STELLA conceptual model based on the ESD. The conceptual model in STELLA does not need to be a copy of the ESD as long as all the parameters that describe the functionality of the system are represented. The purposes of the two tools (i.e. ESD and STELLA) are different and each one emphasizes distinct aspects of the flows of energy through, and the dynamic behavior of, the systems. With the ESD, the intent is to gather a general understanding of the energy flows in the system, whereas the conceptual model in STELLA represents the flows of energy to determine a quantitative variable of state, the temperature in the building.

\section{[Figure 6]}

Fig. 7 shows the dynamic behavior of the architectural system represented in Fig.

6. The simulation indicates that the combination of strategies implemented (i.e. natural ventilation, forced ventilation, envelope performance) regulate the temperature inside the building in a similar way to that observed in the termite mound. Therefore, the above-mentioned strategies implemented in the model will constitute the set of guidelines that the design team will integrate into the project.

\section{[Figure 7]}




\section{Stage 6 - Modeling and benchmarking}

Once the design team has identified the strategies to be implemented in the architectural project the modeling and benchmarking process can be integrated in a traditional design process. This means that the ecomimetic strategies will act as additional design constraints to those imposed by, for example, building codes, budgets, or clients' requirements. However, it might be that some of the ecomimetic strategies cannot be integrated into the design project. In such cases, an iterative process will begin: an assessment of the results obtained from previous stages will be carried out and, when necessary, modifications will be implemented. One deliverable at this stage will be the representation of an architectural system using architectural $2 \mathrm{D}$ and $3 \mathrm{D} \mathrm{CAD}$ tools. The appropriateness of the ecomimetic strategies integrated in the 2D and 3D models can be evaluated at the end of the schematic design phase or early during the design development phase of the project.

The benchmarking of the ecomimetic model requires a baseline for comparison. The design team will have to identify an appropriate baseline for each project. One option is to define a baseline model that does not integrate the ecomimetic strategies; another option might be to use a certification system to define the baseline (e.g. a building that fulfills LEED Gold standards), or use stricter regulations on the building codes. Once the baseline is defined the ecomimetic model will be evaluated in terms of its energy performance and resource use. Software tools for the environmental simulation of buildings (e.g. EnergyPlus, Ecotect) are proposed to assess the performance of the ecomimetic model and the baseline. If the ecomimetic model 
does not present optimized performance when compared against the baseline, then again an iterative exercise will take place. If the environmental performance is above the performance of the selected baseline, then the ecomimetic design process is validated for the specific project under study.

\section{Eastgate Center-Modeling and benchmarking}

It was mentioned at the beginning of this section that the Eastgate Centre was designed and built in 1997, mimicking the strategies that termites use to regulate temperature in their mounds. The environmental performance of the Eastgate Centre has been assessed over the years and this has shown that the building uses $35 \%$ less energy than similar buildings in Harare (Pearce). These results have little relevance in the validation of the ecomimetic method described here because the method was not used in the design of the Eastgate Centre, but they show a recent and successful example of biomimetic design. The current exercise does use the Eastgate Centre, a well-known example in biomimetic literature, to illustrate the use of our ecomimetic method. Existing data about the Eastgate Centre, as well as graphs and models (Figure 2-7), are used to better explain each step of the method. It would be expected that an ecomimetic re-design of the Eastgate Centre would provide different outcomes from those displayed by the actual building. Such an exercise will be developed in the future.

\section{Discussion and Conclusions}


The ecomimetic method has been developed with the aim of becoming a general design method for transferring valuable strategies from ecosystems to buildings. As such, its purpose is not to transfer each and every part of the ecosystem under study, but rather learn from the ecosystem's processes and functions that might help to optimize resource use in buildings. The method draws on theories and approaches in the biomimetic field, but in contrast to previous efforts, the ecomimetic methodology integrates transdisciplinary tools from ecological engineering and systems thinking, and highlights the relevance of thermodynamics in the design process. These considerations stem from the recognition that both buildings and ecosystems are complex, open, thermodynamic systems. This analogy provides a basis for the theoretical support described at each stage of the method. However, this ecomimetic approach is in its infancy and has to be tested under diverse scenarios to be validated as a general design method. This first exercise with the Eastgate Center as a theoretical example shows the potential of the approach in terms of establishing measurable design goals (e.g. thermal regulation between $18^{\circ} \mathrm{C}$ and $23^{\circ} \mathrm{C}$ ), using transdisciplinary tools that convey meaningful information for both ecosystems and buildings (i.e. ESD, STELLA), and presenting a solid theoretical framework for subsequent exercises. In the near future, the method will be tested in the context of an undergraduate course at --- University, and will be used in a professional architectural environment. These case studies will show quantitative results based on the architectural design goals (Stage 1) and compared to the selected baseline (Stage 6). Some challenges that might arise during these exercises are: (1) difficulty identifying 
and defining thermodynamic design goals; (2) problems comprehending the ecological system selected; (3) problems with the identification of feedback structures; (4) lack of data to build the dynamic models; and (5) complications integrating the ecomimetic strategies into the architectural model. It is expected that the exposure of the method to an academic and professional environment will help to address these questions and will bring adjustments and modifications to the ecomimetic design process.

From a philosophical point of view it might be argued that the ecomimetic method falls into a mechanistic and reductionist world-view in that it proposes tools that are able to measure and quantify data (du Plessis, 2012). Tools presented here, like the ESD or STELLA, are analytical in that they allow the representation and understanding of parts of the ecological and building systems. However, these tools also have the ability to integrate all the parts of the system, represent the interactions among these parts, and present the system as a whole. They can also integrate the human component, which is a key element when defining the feedback loops that explain the behavior of an ecological or building system (Authors, 2012). The method can be used within the context of a mechanistic or an ecological world-view, according to the designers' preferences; however, it is the preference of the designers who use the method that determine whether the conceptualization will be mechanistic or holistic. In addition, biomimetic design requires high levels of abstraction to communicate between dissimilar fields of endeavor. As in any modeling exercise, this implies that a certain amount of information will be discarded during the design 
process in order to establish correlations between biological systems (e.g. burrs) and mechanical systems (e.g. Velcro). This might appear as an inaccurate or unclear connection between biology and design if the reader does not have access to all the steps and details of the design process. Therefore, it is very important that the differences and links between the living system (i.e. the ecological system) and the mechanical system (i.e. the building system) are clearly defined during the design process.

The authors consider that the conceptual approach and tools presented here are easily accessible to architects and designers in general, although some training in ecology might be required. Most architectural programs include notions of thermodynamics in their curriculums, which should give some ground for the definition of the thermodynamic design goals during the first stage. The biomimetic databases proposed here are designed to facilitate access to architects and designers. One limitation of these databases for designers might be that the ecological solution selected will be limited to those included in the database. Regarding the use of the ESD, their implementation will require basic knowledge in ecological engineering and familiarity with Odum's work, but the positive aspect is that the diagrams convey information in an appropriate way for professionals and students working with graphic tools. The acquaintance with the dynamic models and, more specifically, the learning of the STELLA software, might represent a financial and time investment, but there are ample pedagogical resources. Other tools proposed here (e.g. AutoCAD) are well known by architects and designers and should not represent an obstacle when 
using the ecomimetic method. However, in order to make the method more accessible to its users, one possible outcome of this research involves the development of a software tool to integrate each stage of the ecomimetic design process. Such a tool should facilitate access to the databases, allow interaction between ESDs and STELLA, and be able to transfer results from STELLA to a CAD format if needed. Although software tools might facilitate the implementation of the method, there are some barriers that might prevent its application. For example, evolution in architectural practice is slow and does not happen uniformly. Successful case studies in the professional environment would attract interest from bigger audiences, and educating students at universities would also create the next generation of biomimetic designers. Another challenge might be found in the budget and time constraints that rule architectural projects. It is expected that an ecomimetic design process will require more time than a sustainable or integrative design process. On top of that, specialists from other fields (i.e. ecologists) might be needed in some cases, which might increase project budgets. Collaboration with universities and research groups might help to reduce some costs during the early implementation of the method, but these challenges will need to be addressed in more detail in the future.

To conclude, the ecomimetic method sets the theoretical framework for a biomimetic design approach inspired by ecosystems. It is a transdisciplinary method that uses a systems thinking approach and that relies on the use of a thermodynamic language to communicate ecosystems and buildings. One of the benefits of implementing this method is its potential for generating innovative design through the 
transfer of knowledge about ecological systems. This goes along with the increasing complexity of architectural systems that has been facilitated by digital tools. Some of these developments might result in new materials or construction systems. Another benefit of implementing the method is the opportunity to optimize resource use in buildings and therefore contribute to reducing GHG emissions and controlling resource scarcity in the building and construction industries. Finally, the application of biomimetic design in architecture is gaining increasing attention from students, professionals and society in general. This research work contributes to the development of the field and more specifically to the application of ecosystem biomimetics.

\section{References:}

Allen, T. (2001). Applying the principles of ecological emergence to building design and construction. In C. J. Kibert, J. Sendzimir \& G. B. Guy (Eds.), Construction Ecology: Nature as a Basis for Green Buildings: Taylor \& Francis.

Ayre, M. (2004). Biomimicry- a review: European Space Agency ESTEC.

BBC Weather. (2013). Average conditions Harare, Zimbabwe. Retrieved August, 2013

Benyus, J. M. (1997). Biomimicry : innovation inspired by nature. New York: Morrow.

Biomimicry 3.8 Institute. (2008). Ask Nature. Retrieved October, 2012

Blanco, J. A. (2010). Seven steps to create ecological models for natural resource management. Retrieved December 9, 2012, from http://www.scitopics.com/Seven steps to create ecological models for natural resource management.html

Brown, M. T. (2004). A picture is worth a thousand words: energy systems language and simulation. Ecological Modelling, 178(1-2), 83-100. doi: 10.1016/j.ecolmodel.2003.12.008

Cheong, H., \& Shu, L. H. (2012, August 12-15, 2012). Automatic Extraction of Causally Related Functions from Natural-Language Text for Biomimetic Design. Paper presented at the ASME International Design Engineering 
Technical Conferences and Computers and Information in Engineering Conference, Chicago,IL.

Cole, R. J. (2012). Regenerative design and development: current theory and practice. Building Research and Information, 40(1), 1-6. doi: 10.1080/09613218.2012.617516

Dewulf, J., Van Langenhove, H., Muys, B., Bruers, S., Bakshi, B. R., Grubb, G. F., .. . Sciubba, E. (2008). Exergy: Its Potential and Limitations in Environmental Science and Technology. Environmental Science \& Technology, 42(7), 2221-2232. doi: 10.1021/es071719a

DTI, (Department of Trade and Industry) (2007). Biomimetics: strategies for product design inspired by nature - a mission to the Netherlands and Germany. Report of a DTI GlobalWatchMission.

du Plessis, C. (2011). Towards a regenerative paradigm for the built environment. Building Research \& Information, 40(1), 7-22. doi: 10.1080/09613218.2012.628548

Fayemi, P.-E., Maranzana, N., Aoussat, A., \& Bersano, G. (2013). Contextualisation des outils biomimetiques afin de developper une nouvelle methodologie. Paper presented at the Confere 2013, Biarritz.

Fernandez-Galiano, L. (1991). El fuego y la memoria: sobre architectura y energía (1 ed.). Madrid: Alianza Editorial.

Ford, A. (2010). Modeling the environment. Washington, DC: Island Press.

Forrester, J. W. (1995). The beginning of system dynamics. McKinsey Quarterly(4), 4-16.

Freitas Salgueiredo, C. (2013). Modeling inspiration for innovative NPD: lessons from biomimetics. Paper presented at the IPDMC'13.

Gamage, A., \& Hyde, R. (2012). A model based on Biomimicry to enhance ecologically sustainable design. Architectural Science Review, 55(3), 224235. doi: 10.1080/00038628.2012.709406

The authors (2012)

Gebeshuber, I. C., Gruber, P., \& Drack, M. (2009). A gaze into the crystal ball: biomimetics in the year 2059. Proceedings of the Institution of Mechanical Engineers, Part C: Journal of Mechanical Engineering Science, 223(12), 2899-2918. doi: 10.1243/09544062jmes1563

Gruber, P. (2011a). Biomimetics -- materials, structures and processes examples, ideas and case studies Retrieved from /z-wcorg/ database Retrieved from http://site.ebrary.com/id/10483975

Gruber, P. (2011b). Biomimetics in architecture architecture of life and buildings. Vienna; New York: Springer.

Guy, S., \& Farmer, G. (2001). Reinterpreting sustainable architecture: the place of technology. Journal of Architectural Education, 54(3), 140.

Hastrich, C. (2006). The biomimicry design spiral. Biomimicry Newsletter, 4(1), 56. 
http://biomimicry.typepad.com/newsletter/files/biomimicry newsletter v4.1.pdf

Helms, M., Vattam, S. S., \& Goel, A. K. (2009). Biologically inspired design: process and products. Design Studies, 30(5), 606-622. doi: 10.1016/j.destud.2009.04.003

Jacklyn, P. (1992). "Magnetic" termite mound surfaces are oriented to suit wind and shade conditions. Oecologia, 91(3), 385-395. doi: $10.1007 / \mathrm{BF} 00317628$

Jan, K., \& Thomas, S. (2012). Design and construction principles in nature and architecture. Bioinspiration \& Biomimetics, 7(1), 015002.

John, G., Clements- Croome, D., \& Jeronimidis, G. (2005). Sustainable building solutions: a review of lessons from the natural world. Building and Environment, 40(3), 319-328. doi: 10.1016/j.buildenv.2004.05.011

Jørgensen, S. E., \& Svirezhev, Y. (2004). Towards a thermodynamic theory for ecological systems. Amsterdam; Boston: Elsevier.

Kay, J. J. (2001). On complexity theory, exergy, and industrial ecology. In C. J. Kibert, J. Sendzimir \& G. B. Guy (Eds.), Construction Ecology: Nature as a Basis for Green Buildings: Taylor \& Francis.

Kay, J. J., Regier, H. A., Boyle, M., \& Francis, G. (1999). An ecosystem approach for sustainability: addressing the challenge of complexity. Futures, 31(7), 721-742.

Kibert, C. J., Sendzimir, J., \& Guy, B. (2000). Construction ecology and metabolism: natural system analogues for a sustainable built environment. Construction Management and Economics, 18(8), 903-916. doi: $10.1080 / 014461900446867$

Kofoid, C. A. T. i. c. (1934). Termites and termite control. Berkeley: University of California Press.

Lazarus, M. A., \& Crawford, C. (2011). Returning Genius to the Place. Architectural Design, 81(6), 48-53. doi: 10.1002/ad.1319

Lenau, T. (2009). Biomimetics as a design methodology possibilities and challenges. from http://orbit.dtu.dk/en/publications/biomimetics-as-adesign-methodology--possibilities-and-challenges(fa4d2713-aa23-4dccadc5-adce49e0e2fa).html

Lepora, N. F., Verschure, P., \& Prescott, T. J. (2013). The state of the art in biomimetics. Bioinspiration and Biomimetics, $8(1)$.

Li, D., Zhu, J., Hui, E. C. M., Leung, B. Y. P., \& Li, Q. (2011). An emergy analysisbased methodology for eco-efficiency evaluation of building manufacturing. Ecological Indicators, 11(5), 1419-1425. doi: 10.1016/j.ecolind.2011.03.004

Mang, P., \& Reed, B. (2014). The nature of positive. Building Research \& Information, 43(1), 7-10. doi: 10.1080/09613218.2014.911565

Meadows, D. H., \& Wright, D. (2008). Thinking in systems : a primer. White River Junction, Vt.: Chelsea Green Pub. 
Mumford, L. (1934). Technical Syncretism and Towards and Organic Ideology. In W. W. Braham, J. A. Hale \& J. S. Sadar (Eds.), Rethinking technology a reader in architectural theory. London; New York: Routledge.

Nachtigall, W. (1997). Vorbild Natur. Bionik - Design für funktionelles Gestalten: Springer.

Odum, E. P. (1977). The emergence of ecology as a new integrative discipline. Science, 195(4284), 1289.

Odum, H. T. (1994). Ecological and general systems: an introduction to systems ecology: University Press of Colorado.

Odum, H. T. (2001). Material circulation, energy hierarchy, and building construction. In C. J. Kibert, J. Sendzimir \& G. B. Guy (Eds.), Construction Ecology: Nature as a Basis for Green Buildings: Taylor \& Francis.

Odum, H. T. (2007). Environment, power, and society for the twenty-first century: the hierarchy of energy. New York: Columbia University Press.

Odum, H. T., \& Peterson, N. (1996). Simulation and evaluation with energy systems blocks. Ecological Modelling, 93(1-3), 155-173. doi: 10.1016/0304-3800(95)00221-9

Pearce, M. Eastgate development Harare. Retrieved September 19, 2014, from http://www.mickpearce.com/works/office-public-buildings/eastgatedevelopment-harare/

Pedersen Zari, M. (2007). Biomimetic approaches to architectural design for increased sustainability (paper no. 033).

Pedersen Zari, M. (2011). Ecosystem services analysis for the design of regenerative built environments. Building Research \& Information, 40(1), 54-64. doi: 10.1080/09613218.2011.628547

Pedersen Zari, M. (2012). Ecosystem Services analysis for the design of regenerative urban built environments. (PhD Thesis), Victoria University of Wellington, Wellington, New Zealand.

Pedersen Zari, M. (2014). Ecosystem processes for biomimetic architectural and urban design. Architectural Science Review, 1-14. doi: 10.1080/00038628.2014.968086

Pedersen Zari, M., \& Storey, J. (2007). An ecosystem based biomimetic theory for a regenerative built environment. I OS PRESS, 620-627.

Peters, T. (2011). Nature as Measure: The Biomimicry Guild. Architectural Design, 81(6), 44-47. doi: 10.1002/ad.1318

Pomeroy, L. R., \& Alberts, J. J. (1988). Concepts of Ecosystem Ecology a Comparative View. from http://dx.doi.org/10.1007/978-1-4612-3842-3

Prigogine, I. (1968). Introduction to thermodynamics of irreversible processes. New York: Interscience Publishers.

Purves, W. K. (2001). Life, the science of biology. Sunderland, MA: Sinauer Associates. 
Schmidt, A. M., Jacklyn, P., \& Korb, J. (2014). 'Magnetic' termite mounds: is their unique shape an adaptation to facilitate gas exchange and improve food storage? Insectes Sociaux, 61(1), 41-49. doi: 10.1007/s00040-013-0322-6

$\mathrm{Shu}, \mathrm{L} . \mathrm{H}$. (2010). A natural-language approach to biomimetic design. Artificial Intelligence for Engineering Design, Analysis and Manufacturing, 24, 507519. doi: 10.1017/S0890060410000363

Shu, L. H., Ueda, K., Chiu, I., \& Cheong, H. (2011). Biologically inspired design. CIRP annals, 60(2), 673-693.

Speck, T., \& Speck, O. (2008). Process sequences in biomimetic research. WIT tran, 114, 3-11.

Srinivasan, R. S., Braham, W. W., Campbell, D. E., \& Curcija, C. D. (2012). Re(De)fining Net Zero Energy: Renewable Emergy Balance in environmental building design. Building and Environment, 47(0), 300315. doi: 10.1016/j.buildenv.2011.07.010

Srinivasan, R. S., Ingwersen, W., Trucco, C., Ries, R., \& Campbell, D. (2014). Comparison of energy-based indicators used in life cycle assessment tools for buildings. Building and Environment, 79(0), 138-151. doi: http://dx.doi.org/10.1016/i.buildenv.2014.05.006

Thompson, B. P., \& Bank, L. C. (2010). Use of system dynamics as a decisionmaking tool in building design and operation. Building and Environment, 45(4), 1006-1015. doi: http://dx.doi.org/10.1016/j.buildenv.2009.10.008

Turner, J. S. (2001). On the Mound of Macrotermes michaelseni as an Organ of Respiratory Gas Exchange. Physiological and Biochemical Zoology, 74(6), 798-822. doi: 10.1086/323990

Turner, J. S., \& Soar, R. C. (2008). Beyond biomimicry: What termites can tell us about realizing the living building. Paper presented at the First International Conference on Industrialized, Intelligent Construction (I3CON), Loughborough University, Leicestershire, UK.

United Nations (1992). Chapter 8. Convention on Biological Diversity. Ch XXVII 8. U. Nations. Rio de Janeiro 5 June 1992.

UNEP, S. B. C. I. (2009). Buildings and Climate Change.

UNEP, S. B. C. I. (2010). Common Carbon Metric: Protocol for Measuring Energy Use and Reporting Greenhouse Gas Emissions from Building Operations. Draft for pilot testing.

Vincent, J. (2003). Biomimetic modelling. Philosophical Transactions of the Royal Society of London. Series B: Biological Sciences, 358(1437), 1597-1603. doi: 10.1098/rstb.2003.1349

Vincent, J., Bogatyreva, O. A., Bogatyrev, N. R., Bowyer, A., \& Pahl, A.-K. (2006). Biomimetics: its practice and theory. Journal of The Royal Society Interface, 3(9), 471-482. doi: 10.1098/rsif.2006.0127

Vincent, J., \& Mann, D. L. (2002). Systematic technology transfer from biology to engineering. Philosophical Transactions of the Royal Society of London. 
Series A: Mathematical, Physical and Engineering Sciences, 360(1791), 159-173. doi: 10.1098/rsta.2001.0923

von Bertalanffy, L. (2008). An Outline of General System Theory. Emergence: Complexity \& Organization, 10(2), 103-123.

Wasfi, A. (2014). Architecture as a Second Nature. Journal of Sustainable Architecture and Civil Engineering, 7(2).

Wilson, J. O. (2008). A systematic approach to bio-inspired conceptual design. (Ph.D.), Georgia Institute of Technology, Unpublished. Retrieved from https://smartech.gatech.edu/handle/1853/26483

Worall, M. (2011). Homeostasis in nature: Nest building termites and intelligent buildings. Intelligent Buildings International, 3(2), 87-95. doi:

10.1080/17508975.2011.582316 